\title{
Automatic monitoring of plateau and driving pressure during pressure and volume controlled ventilation
}

\author{
F Mojoli, M Pozzi, S Bianzina, G Tavazzi, A Orlando, S Mongodi, F Torriglia, A Braschi \\ From ESICM LIVES 2015 \\ Berlin, Germany. 3-7 October 2015
}

\section{Introduction}

Plateau pressure (Pplat) limitation is routinely used to avoid ventilator-induced lung injury. Recently, driving pressure $(\Delta \mathrm{P})$ was strongly associated with survival in ARDS patients [1].

\section{Objectives}

To evaluate the feasibility of $\Delta \mathrm{P}$ and Pplat continuous monitoring during volume (VCV) and pressure (PCV) controlled ventilation, we compared with gold standard (occlusion maneuvers at end-inspiration and end-expiration) two different methods: 1- Least Square Fitting (LSF) method that provide maneuver-free Pplat and $\Delta \mathrm{P}$ values; 2 - Mini Occlusion (MO) method by performing brief occlusion maneuvers.

\section{Methods}

We enrolled 22 patients admitted to our ICU after scheduled major abdominal surgery, with normal or restrictive respiratory system mechanics under pressure (12 pts) and volume (10 pts) controlled mechanical ventilation (G5, Hamilton Medical). We studied 12 different conditions in each patient by changing respiratory rate (10-15-20-25 bpm) and I:E ratio (1:2, 1:1, 2:1). Inspiratory pressure in $\mathrm{PCV}$ and tidal volume (TV) in VCV were adjusted to keep end-tidal $\mathrm{CO}_{2}$ between 32 and $36 \mathrm{mmHg}$. PEEP and $\mathrm{FiO}_{2}$ were set to maintain $\mathrm{SpO}_{2} \geq 95 \%$. $\triangle \mathrm{P}$, Pplat and PEEPtot reference values $\left(\Delta \mathrm{P}_{\mathrm{REF}}\right.$, Pplat $\mathrm{REF}_{\text {RE }}$ and PEEPtot $\left.\mathrm{REF}_{\mathrm{REF}}\right)$ for each ventilatory setting were obtained by $5 \mathrm{~s}$-length occlusion maneuvers at end-inspiration and end-expiration $\left(\Delta \mathrm{P}_{\mathrm{REF}}=\right.$ Pplat $_{\text {REF }}$ - PEEPtot $\left.{ }_{\text {REF }}\right) . \Delta \mathrm{P}_{\mathrm{MO}}$ values were calculated as:

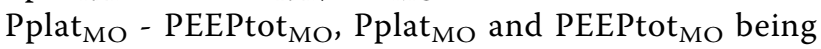

average airway pressure in the last $100 \mathrm{~ms}$ of miniocclusion maneuvers lasting $400 \mathrm{~ms}$. LSF applied over the whole respiratory cycle provided Pplat ${ }_{\mathrm{LSF}}$ and $\mathrm{Crs}_{\mathrm{LSF}}$ values, being $\mathrm{Crs}$ the compliance of the respiratory system. $\Delta \mathrm{P}_{\mathrm{LSF}}$ was calculated as $\mathrm{TV} / \mathrm{Crs} \mathrm{LSF}_{\mathrm{LF}}$.

\section{Results}

Difference with reference values was greater for $\mathrm{MO}$ vs. LSF, both for $\Delta \mathrm{P}\left(0.82 \pm 0.41\right.$ vs. $0.46 \pm 0.82 \mathrm{cmH}_{2} \mathrm{O}$, respectively; $\mathrm{p}<0.001)$ and Pplat $(0.52 \pm 0.33$ vs. $0.02 \pm$ $0.49 \mathrm{cmH}_{2} \mathrm{O} ; \mathrm{p}<0.001$ ).

\section{Conclusions}

Both methods provided a good estimation of $\Delta \mathrm{P}$ and Pplat; MO showed a slightly better precision than LSF, but a greater bias, being these differences not clinically relevant. Anyway, LSF is a totally continuous and non invasive method, whereas MO method minimally interferes with mechanical ventilation and its implementation on ICU ventilators could be more troublesome.

Published: 1 October 2015

\section{Reference}

1. Amato BPMarcelo, et al: Driving pressure and survival in the acute respiratory distress syndrome. N Eng J Med 2015, 372:747-55.

\section{doi:10.1186/2197-425X-3-S1-A998}

Cite this article as: Mojoli et al: Automatic monitoring of plateau and driving pressure during pressure and volume controlled ventilation. Intensive Care Medicine Experimental 2015 3(Suppl 1):A998. 